\title{
A systematic review of adult admissions to ICUs related to adverse drug events
}

\author{
Pierre-Alain Jolivot ${ }^{1,2,3}$, Patrick Hindlet ${ }^{1,2,3,4}$, Claire Pichereau ${ }^{5}$, Christine Fernandez ${ }^{1,2,3,4}$, Eric Maury ${ }^{1,2,5}$, \\ Bertrand Guidet ${ }^{1,2,5}$ and Gilles Hejblum ${ }^{1,2,6^{*}}$
}

\begin{abstract}
Adverse drug events (ADE) may lead to hospital admission, and in some cases admission to an ICU is mandatory. We conducted a systematic review dealing with the incidence of ADE requiring ICU admission in adult patients, the reference population being all ICU admissions. Medline, Embase and Web of Science databases were screened from January 1982 to July 2014, using appropriate key words. Only original articles in English reporting the incidence of ADE requiring ICU admission in adult patients among total ICU admissions were included. Article eligibility was assessed by two independent reviewers, a third being involved in cases of disagreement. All reported characteristics (type of ICU, characteristics of patients, incidence of ADE, severity and preventability, drugs involved, causality) in the selected articles were collected for the review. The quality of studies was independently assessed by two reviewers with a specific score that we developed. A meta-analysis was conducted. Inclusion criteria were fulfilled by 11 studies out of the 4,311 identified in the initial literature search. The median (interquartile) quality score was $0.61(0.44 ; 0.69)$. The reported incidences of ADE requiring ICU admission in adult patients ranged from 0.37 to $27.4 \%$, with an associated mortality rate ranging from 2 to $28.1 \%$ and a mean length of stay ranging from 2.3 to 6.4 days. Preventable events accounted for 17.5 to $85.7 \%$ of the events. Costs and mechanisms at the root of ADE were investigated in only two and five studies, respectively. The forest plot examining the incidence of ADE requiring ICU admission in adult patients was associated with high heterogeneity ( $P^{2}$ statistic $>98 \%$ ), and the shape of the corresponding funnel plot was asymmetric. Heterogeneity across studies concerned many features, including studied populations, events considered, causality assessment methods, definitions of preventability and severity. Despite the heterogeneity of the reports, our review indicates that ICU admission due to ADE is a significant issue that should deserve further interest. The review led us to propose a list of items devoted to the reporting of future studies on ADE requiring ICU admissions.
\end{abstract}

\section{Introduction}

The incidence of hospital admissions required because of adverse drug events (ADE) has been reported to range from 0.16 to $15.7 \%$ with an overall median of $5.3 \%$ [1]. Some serious ADE may require ICU admission. Such unplanned admissions may have consequences for the healthcare system because they may deleteriously overload the ICU and restrain ICU access to other patients. Since ICU admissions generate high costs, with per-capita expenditures ranging from US\$730 to 7,410 [2], while the need for critical care capacity is increasing [3], a just and effective rationing of

\footnotetext{
* Correspondence: gilles.hejblum@inserm.fr

'Institut Pierre Louis d'Epidémiologie et de Santé Publique, Sorbonne Universités, UPMC Univ Paris 06, UMR_S 1136, F-75013 Paris, France ${ }^{2}$ Institut Pierre Louis d'Epidémiologie et de Santé Publique, INSERM, UMR_S 1136, F-75013 Paris, France

Full list of author information is available at the end of the article
}

critical care is an issue that all western industrialised countries have to consider. The abovementioned context suggests documenting the incidence of medication-related ICU admissions and the drug management problem involved. Identifying specific patterns in the population of patients admitted to the ICU for ADE - for example, in terms of mortality during ICU stay or after discharge - also constitutes an attractive issue. To gain more insight into all of these issues, we performed a systematic review of the literature on ICU admissions required because of ADE. In this review, we adopted an ICU perspective: the reference with which ICU admissions required because of ADE were contrasted had to be all ICU admissions (not the population of hospitalised patients, for example). In the following text, the incidence of drug-related ICU admissions (IDRIA) will be referred to as the ratio of the number of ICU admissions 
required because of $\mathrm{ADE}$ to the total number of ICU admissions.

As a preliminary, some issues on definitions related to ADE have to be tackled. The terminology of events related to drug harm is complex because many terms have been used in the literature [4]. A definition of ADE was proposed by the Institute of Medicine and was recommended by Nebeker and colleagues [4]: 'any injury resulting from medical intervention related to a drug'. This broad definition includes both harm caused by the drug itself (that is, adverse drug reaction (ADR), or harm related to the accumulation of drugs in the case of renal or liver failure) and harm resulting from the use of a drug (that is, medication errors). According to the World Health Organization, an ADR is defined as any noxious, unintended or undesired effect of a drug occurring at dosages administered in humans for prophylaxis, diagnosis or treatment [5]. A medication error is 'any preventable event that may cause or lead to inappropriate medication or patient harm while the medication is in control of health care professional, patient or consumer' [4]. An iatrogenic event (also called an adverse event) will be considered as any injury related to medical management, in contrast to complications of disease. Medical management includes all aspects of care, including diagnostic and treatment, failure to diagnose or treat, and the systems and equipment used to deliver care' [6].

\section{Methods \\ Eligibility criteria}

The eligibility criteria for inclusion in the review included: original articles in English (reviews, conference abstracts and case reports were excluded); a patient population over 14 years old; hospitalisation in any type of adult ICU (for example, medical, surgical, cardiac, and so forth); main outcome focusing on the ADE as a cause of admission to the ICU, whatever the patients' origin (home, emergency department, hospital ward), the reference population being all ICU admissions; articles included a description of the incidence of all ICU admissions due to $\mathrm{ADE}$, the reference denominator being the total number of ICU admissions; and articles focusing on admissions to the ICU only due to selfpoisoning were excluded.

\section{Information sources}

On 4 July 2014 we conducted a combined search in the Embase database, in the Medline database via PubMed and in the Web of Science. Using relevant search terms related to ADE responsible for admissions to the ICU, we searched for all publications in English from 1 January 1982 to 4 July 2014. Complementary searches were made to identify potential additional articles: the reference lists of retrieved articles as well as their citing lists (the latter being issued from the Web of Science) were handsearched.

\section{Search strategy}

The queries made in the PubMed, Embase and Web of Science databases are detailed in Additional file 1.

\section{Study selection}

The eligibility of each retrieved article was independently assessed by two reviewers (PAJ and $\mathrm{PH})$ on the title, abstract and, if necessary, full text. We a priori decided that in the case of disagreement, a third reviewer $(\mathrm{GH})$ would decide whether to include the study or not.

\section{Data collection process}

A standardised data collection sheet was elaborated by three reviewers (PAJ, PH and GH). One reviewer (PAJ) fulfilled this data collection sheet and another (PH) checked the extracted data. In case of disagreements, the third reviewer $(\mathrm{GH})$ would decide.

\section{Data items}

The list of data items collected in each study is presented in Table 1. Examination of all features reported was used for proposing a list of items that we judged to deserve a mention in articles related to ADE requiring ICU admissions. We redefined the numerous terms related to $\mathrm{ADE}$ mentioned in the selected articles using only three terms, namely ADE, ADR and medication errors (defined in Introduction). All costs were normalised in 2014 US dollars and were discounted at an annual rate of $3 \%$.

\section{Risk of bias assessment}

To assess the risks of bias in individual studies, a specific list of items adapted to the scope of ADE responsible for ICU admission was designed by three authors (PAJ, PH and $\mathrm{CP}$ ). The list was based on a combination of Strengthening the Reporting of Observational Studies in Epidemiology (STROBE) [7] and Preferred Reporting Items for Systematic Reviews and Meta-Analyses (PRISMA) [8] items. Two of us (PAJ and $\mathrm{PH}$ ) independently assessed each individual study by granting for each item either 1 point when reporting of corresponding data was complete or 0 points when corresponding data were missing or reporting was incomplete (disagreements were solved by consensus discussion). Scores per study (proportion of items completely reported) were considered for assessing the risk of bias in individual studies. Scores per item (proportion of studies with the item completely reported) were considered for assessing the risk of bias across studies (risk of bias decreases with increasing score values), as was a funnel plot representing study size against the 


\section{Table 1 Data items collected for the review}

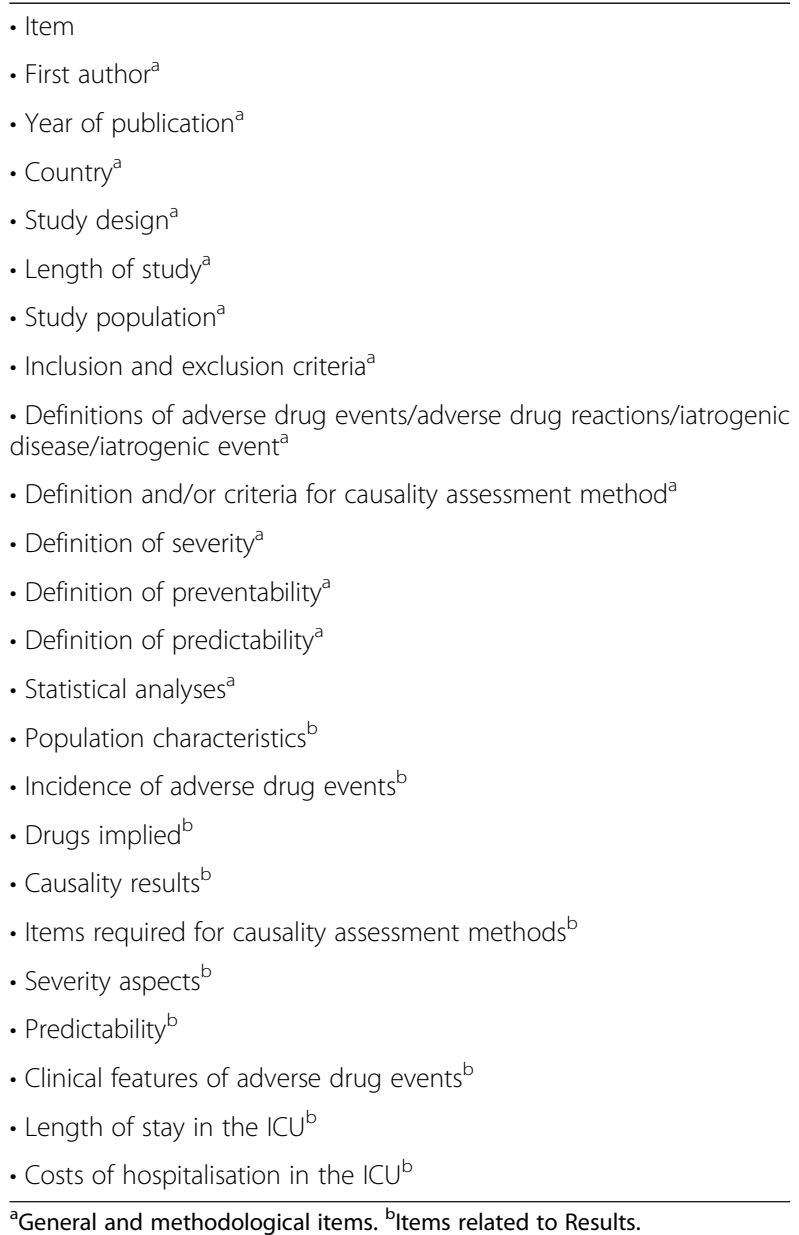

incidence of ADE. The symmetry of the plot was visually assessed.

\section{Summary measures}

The main measure of our study was the IDRIA. The IDRIA estimate was either directly extracted from the source document or was calculated. The same process was used for obtaining the preventability rate.

\section{Synthesis of results}

Funnel and forest plot analyses were conducted, and risk of bias and heterogeneity across studies were investigated. All analyses were performed using the meta package within $\mathrm{R}$ statistical software [9].

\section{Additional analysis Quality assessment}

Risk of bias and quality of reporting are two different notions. We assessed the quality of reporting in the selected articles using a score based on the STROBE checklist; that is, on the quality of reporting items that should be addressed in reports of observational studies [7]. If information on a given item was completely reported in the studied article, 1 point was granted; 0 points were attributed if this information was incomplete or missing. Whenever an item was not applicable for a study, the item was not considered for calculating the study's score (that is, number of points granted/number of points considered).

In addition, to propose a more specific assessment of the quality in studies reporting the IDRIA, we designed a specific checklist (Table 2) derived from the STROBE checklist, and the quality of reporting of the studies based on this checklist was assessed. Item scores were weighted according to our feeling about item importance, with a highest number of points ( 3 points) attributed to risk of bias items, and with a binary decision for each item (that is, no grading: either all points associated with the item score granted, or none). For each article, the sum of all points was calculated and the total score was defined as the ratio of the number of points granted to the maximum possible score (excluding nonapplicable items). Quality appraisal therefore varied from 0 to 1 , with a score increase corresponding to a quality increase. Scoring was independently assessed by two reviewers (PAJ and $\mathrm{PH}$ ), and we a priori decided that in a case of disagreement a third reviewer $(\mathrm{GH})$ would decide whether to grant the point(s) on a given item.

\section{Sensitivity analysis}

To investigate heterogeneity in detail, analyses were conducted in which one or several included studies were removed. Such analyses included funnel and forest plots, and assessment of the $I^{2}$ statistic.

\section{Results}

Study selection

The initial queries yielded a total of 4,311 initial records (Figure 1). Among the 50 articles assessed for eligibility, fulltext reading resulted in the exclusion of 39 (see Additional file 2 for exclusion reasons). The whole process resulted in the selection of 11 articles [10-20]. A particular article raised concerns for selection: a multicentre study gathering results from eight ICUs, one of which was a paediatric ICU. However, both reviewers selected this article because of the limited impact of the paediatric ICU in the global results of this multicentre study [15]. A disagreement requiring a third reviewer concerned only one article [12]. Neither the examination of the reference lists of the selected articles nor that of their citing lists $(n=183$ new references screened and assessed for eligibility) resulted in the retrieval of any additional article finally included in the review.

\section{Study characteristics}

The 11 selected studies were published between 1986 and 2012 and were performed in different countries, types of hospital and ICUs (Table 3). Various features were 
Table 2 Quality assessment according to specific criteria on adverse drug events responsible for ICU admission

\section{Item}

Title

Explicit topic

\section{Abstract}

Type(s) of ICU studied

Causality assessment method(s)

Proportion of patients admitted to the ICU for ADE

Preventability rate of ADE

Study duration

\section{Introduction}

Background

Objectives

\section{Methods}

Mandatory

Description of the study design

Type(s) of ICU studied

Complementary information on the setting environment

Description of the study size rationale

Definition of ADE

Evaluation of inter-rater reliability for inclusion decision

Description of evaluators' training

Description of patients' screening

Description of inclusion/exclusion criteria

Description of collected data and outcomes measured

Description of drug history collecting method

Description of causality assessment method(s)

Description of preventability method/criteria

Definition of the severity

Study duration

Not mandatory
Recommendation

Points granted

One must understand that the article concerns ADE that require ICU

2 admissions

Describe the type of ICU (for example, medical, surgical) 2

Indicate the causality assessment method(s) used 2

The denominator should be the total number of patients admitted in the 2 studied ICU during the observation period

Indicate the estimated preventability rate of ADE

Indicate the study observation period(s)

Explain the scientific background and rationale for the investigation being reported

State the objectives of the study

A prospective patient screening is preferred in order to avoid missing data 3

Describe the type of ICU(s) (for example, medical, surgical)

Indicate the presence of eventual other ICU(s) in the hospital, and mention specific wards (oncology, haematology, geriatrics). This information may help in appraising and understanding results

Study size should be argued 3

The definition of the institute of medicine and recommended by Nebeker 3 and colleagues [4] should be preferred

Indicate how inter-rater reliability for inclusion decision was assessed

Describe the profession of evaluators and, if applicable, participation in specific training for the study

Describe who was in charge of the patients' screening and how screening 3 was performed

Describe and justify inclusion and exclusion criteria 3

Collected data should include characteristics of study participants (age, gender, severity score at admission (SOFA/SAPS II), number and classes of $\operatorname{drug}(\mathrm{s})$ involved; see items in Results)

Describe the sources of data used for establishing drug history, including all patients' prescriptions (home, hospital). If possible, the patient or a relative should be questioned to identify all drugs prescribed, all drugs taken in selfmedication and drugs prescribed but not taken (inobservance) during the month prior to ICU admission. If patients were already hospitalised before ICU admission, all drugs administered during the hospital stay should be collected

Mention the causality assessment method(s) used. Assessment of inter-rater reliability would be welcome

Mention the criteria used for assessing preventability. Assessment of inter-rater 3 reliability would be welcome

Mention the severity of the ADE: fatal (ADE contributed to death), lifethreatening (ADE requiring organ supply) and moderate (ADE only requiring monitoring)

Mention the date of beginning and ending of the study 


\section{Table 2 Quality assessment according to specific criteria on adverse drug events responsible for ICU admission} (Continued)

Description of statistical analysis (if applicable)
Research of medical causes that contributed to
ADE (for preventable drug events)

Results

Mandatory

Proportion of patients admitted to the ICU for ADE according to the chosen denominator

Results for inter-rater reliability for inclusion decision

Description of the characteristics of patients with ADE

Number and classes of drugs suspected to be involved in the ADE responsible for ICU admission

Results for causality assessment

Results for the preventability rate of $\mathrm{ADE}$

Results for severity of ADE

Results for ICU mortality rate of patients with and without ADE (separately)

Length of stay in ICU of patients with and without ADE (separately)

Not mandatory

Results of inter-rater reliability for causality and preventability

Research of medical causes that contributed to ADE (for preventable ADE)

Number of drugs taken by patients with ADE prior to ICU admission

Clinical features of ADE

Comorbidities of patients with ADE

Discussion

Limitations

Interpretation
Describe all statistical methods, if applicable

0.5

Indicate how the medical causes that contributed to ADE were investigated (that is, drug interactions, contraindications between drugs and patient's disease, nonappropriate dosage)

0.5
The chosen denominator should be the total number of included patients admitted to the ICU during the study observation period

Describe the analysis results of inter-rater agreements/disagreements 3

Describe the studied population: age, gender, severity score at admission, 3 reason for admission, origin of patients (home, hospital)

The Anatomical Therapeutic Chemical classification should be used

Provide all causality assessment results

3

Indicate the estimated preventability rate of ADE

Indicate how many patients died and how many required organ support

Indicate and compare the ICU mortality rates of patients with and without

ADE. Estimates of the hospital mortality rates for these patients would also be welcome

Indicate and compare the lengths of stay in the ICU for patients with and without ADE

Describe the analysis results of inter-rater agreements/disagreements

For preventable ADE, investigations into the medical causes that contributed to $A D E$, such as prescription despite contraindication, dosage nonappropriate according to weight or specific pathologies (that is, renal impairment) may constitute valuable data to report

The total number of drugs taken by patients with ADE prior to ICU admission would be welcome, as well as drugs prescribed but not taken

Describe all clinical features of ADE

Describe comorbidities of patients with ADE

Discuss limitations of the study, taking into account sources of potential bias Interpret results and compare with previous studies

ADE, adverse drug events; SAPS II, Simplified Acute Physiology Score II; SOFA, Sequential Organ Failure Assessment.

reported, including incidence, cause, causality, risk factors, severity, preventability, length of stay and costs.

\section{Risk of bias within studies}

The scores of individual studies for the risk of bias ranged from 0.33 to 0.79 (Table 4), with six studies [10,13,16-18,20] having a score above 0.5 (one-half of the items completely reported) and five studies a score below $0.5[11,12,14,15,19]$.

\section{Results of individual studies}

Population characteristics

Inclusion and exclusion criteria were specified in nine studies and were heterogeneous across studies. The mean length of ICU stay for patients admitted to the
ICU because of ADE was reported in five articles [13,16-18,20] and varied from 2.3 days [18] to 6.4 days [16]. In the study by Nazer and colleagues performed in Jordan, the average discounted cost (hospital bill for patient charge normalised in 2014 US dollars) for the management of an ICU admission related to ADE would amount to $\$ 10,388$ with a median cost of $\$ 4,785$ [20]. According to the payer's perspective adopted in the study by Darchy and colleagues performed in France, the average discounted cost of an ICU admission related to $\mathrm{ADE}$ (including iatrogenic events related to surgery or procedures) would amount to $\$ 5,606$ [13].

Patients specifically admitted to the ICU for ADE were compared with patients admitted to the ICU for reasons 


\section{Identification}

Records identified through database screening $\mathrm{n}=5190$ :

Embase $n=4000$; Medline $n=566$; Web Of Science $n=624$

Records screened after duplicate removal: $n=4311$

Screening

Records screened on publication type: $n=4311$

Records excluded (not original articles) $n=2554$

Original articles screened on the basis of title and abstract: $n=1757$

Records excluded: $\mathrm{n}=1707$ :

Off-topic: $\mathrm{n}=1267$

Paediatrics: $n=426$

Self-poisoning: $\mathrm{n}=14$

\section{Eligibility}

Full-text articles assessed for eligibility: $n=50$

Records excluded: $\mathrm{n}=39$

ADE occurring during ICU stay: $n=25$

ADE leading to ICU not the main outcome: $n=9$

Incidence of ADE leading to ICU not reported/not calculable: $n=2$

Not all ICU admissions due to ADE considered: $\mathrm{n}=2$

Preliminary results: $\mathrm{n}=1$

Eligible articles: $\mathrm{n}=11$

\section{Included}

Complementary searches (did not result to any additional article inclusion): $\mathrm{n}=183$ new references

Bibliography of the 11 eligible articles

Articles citing the 11 eligible articles

Studies included in the qualitative synthesis: $\mathrm{n}=11$

Figure 1 Flow diagram of the literature search. $A D E$, adverse drug events. 
Table 3 Design and aims of the selected studies

\begin{tabular}{|c|c|c|c|c|c|c|c|}
\hline Study & Country & Study duration & Study design & $\begin{array}{l}\text { Type of } \\
\text { hospital }\end{array}$ & Type of ICU & $\begin{array}{l}\text { Number of patients } \\
\text { admitted during } \\
\text { studied period }\end{array}$ & Aims of the study \\
\hline $\begin{array}{l}\text { Trunet and } \\
\text { colleagues, } \\
1986[10]\end{array}$ & France & $\begin{array}{l}33 \text { months } \\
\text { (August } 1978 \text { to } \\
\text { April 1981) }\end{array}$ & $\begin{array}{l}\text { Prospective } \\
\text { monocentre }\end{array}$ & $\begin{array}{l}\text { Teaching } \\
\text { hospital }\end{array}$ & Multidisciplinary ICU & 1,651 & $\begin{array}{l}\text { Determine cause and effect relationship between drugs and adverse } \\
\text { event, severity of DII, role of underlying disease and potential } \\
\text { preventability of DII }\end{array}$ \\
\hline IGICE, 1987 [11] & Italy & 6 months & $\begin{array}{l}\text { Prospective (data } \\
\text { collection on a } \\
\text { given day each } \\
\text { week) }\end{array}$ & ND & 27 general ICUs & 4,537 & Document aspects of ADR epidemiology in 27 general ICUs \\
\hline $\begin{array}{l}\text { Nelson and } \\
\text { Talbert, } 1996 \\
{[12]}\end{array}$ & USA & $\begin{array}{l}1 \text { month (July to } \\
\text { August 1993) }\end{array}$ & $\begin{array}{l}\text { Prospective } \\
\text { monocentre }\end{array}$ & $\begin{array}{l}\text { Teaching } \\
\text { hospital }\end{array}$ & $\begin{array}{l}\text { Medical ICU, CCU } \\
\text { and internal } \\
\text { medicine service }\end{array}$ & $127^{a}$ & $\begin{array}{l}\text { Describe the frequency and pattern of drug-related morbidity that } \\
\text { results in hospital admission and the extent to which these admis- } \\
\text { sions are avoidable }\end{array}$ \\
\hline $\begin{array}{l}\text { Darchy and } \\
\text { colleagues, } \\
1999 \text { [13] }\end{array}$ & France & $\begin{array}{l}12 \text { months } \\
\text { (January to } \\
\text { December 1994) }\end{array}$ & $\begin{array}{l}\text { Retrospective } \\
\text { monocentre }\end{array}$ & $\begin{array}{l}\text { General } \\
\text { hospital } \\
\text { (500 beds) }\end{array}$ & $\begin{array}{l}\text { Medico-surgical ICU } \\
\text { ( } 15 \text { beds), CCU ( } 6 \\
\text { beds) }\end{array}$ & 623 & $\begin{array}{l}\text { Determine whether aging of the general population and medical } \\
\text { advances have altered the incidence, causes and consequences of } \\
\text { severe IDs, compared with Trunet and colleagues' first study [21] }\end{array}$ \\
\hline $\begin{array}{l}\text { Hammerman } \\
\text { and } \\
\text { Kapeliovich, } \\
2000[14]\end{array}$ & Israel & $\begin{array}{l}36 \text { months (July } \\
1994 \text { to June } \\
\text { 1997) }\end{array}$ & $\begin{array}{l}\text { Prospective } \\
\text { monocentre }\end{array}$ & $\begin{array}{l}\text { Teaching } \\
\text { hospital } \\
\text { (900 beds) }\end{array}$ & CCU (9 beds) & 2,559 & $\begin{array}{l}\text { Evaluate major cardiac iatrogenic disease as the cause of admission } \\
\text { to the } \mathrm{CCU}\end{array}$ \\
\hline $\begin{array}{l}\text { Lehmann and } \\
\text { colleagues, } \\
2005 \text { [15] }\end{array}$ & USA & $\begin{array}{l}12 \text { months } \\
\text { (November } 1998 \\
\text { to November } \\
\text { 1999) }\end{array}$ & $\begin{array}{l}\text { Prospective } \\
\text { monocentre }\end{array}$ & $\begin{array}{l}\text { Four } \\
\text { teaching } \\
\text { hospitals }\end{array}$ & $\begin{array}{l}\text { Four surgical ICUs, } \\
\text { three medical ICUs } \\
\text { and one paediatric } \\
\text { ICU }\end{array}$ & 5,727 & $\begin{array}{l}\text { Identify the frequency and type of iatrogenic medical events } \\
\text { requiring admission to the ICU. Assess the consequences of } \\
\text { iatrogenic medical events for patients, and the incidence of } \\
\text { disclosure of iatrogenic medical events to patients }\end{array}$ \\
\hline $\begin{array}{l}\text { Grenouillet- } \\
\text { Delacre and } \\
\text { colleagues, } \\
2007 \text { [16] }\end{array}$ & France & $\begin{array}{l}6 \text { months (May } \\
\text { to October 2003) }\end{array}$ & $\begin{array}{l}\text { Prospective } \\
\text { monocentre }\end{array}$ & $\begin{array}{l}\text { Teaching } \\
\text { hospital }\end{array}$ & Medical ICU & 436 & $\begin{array}{l}\text { Assess the characteristics of life-threatening ADR in patients admitted } \\
\text { to a medical ICU in order to identify associated risk factors that could } \\
\text { facilitate early identification }\end{array}$ \\
\hline $\begin{array}{l}\text { Rivkin, } 2007 \\
{[17]}\end{array}$ & USA & $\begin{array}{l}19 \text { weeks } \\
\text { (December } 2004 \\
\text { to May 2005) }\end{array}$ & $\begin{array}{l}\text { Prospective } \\
\text { monocentre }\end{array}$ & $\begin{array}{l}\text { Teaching } \\
\text { hospital } \\
\text { (1,076 beds) }\end{array}$ & $\begin{array}{l}\text { Medical ICU (12 } \\
\text { beds) }\end{array}$ & 281 & $\begin{array}{l}\text { Determine frequency, severity and preventability of ADR leading to } \\
\text { admission to a medical ICU }\end{array}$ \\
\hline $\begin{array}{l}\text { Schwake and } \\
\text { colleagues, } \\
2009 \text { [18] }\end{array}$ & Germany & $\begin{array}{l}12 \text { months } \\
\text { (January to } \\
\text { December 2003) }\end{array}$ & $\begin{array}{l}\text { Prospective } \\
\text { monocentre }\end{array}$ & $\begin{array}{l}\text { Teaching } \\
\text { hospital } \\
\text { (1,685 beds) }\end{array}$ & $\begin{array}{l}\text { Medical ICU ( } 14 \\
\text { beds) }\end{array}$ & 1,554 & $\begin{array}{l}\text { Determine the incidence of ICU admissions due to ADR and compare } \\
\text { affected patients with patients admitted to the ICU for the treatment } \\
\text { of deliberate self-poisoning using medical drugs }\end{array}$ \\
\hline $\begin{array}{l}\text { Mercier and } \\
\text { colleagues, } \\
2010 \text { [19] }\end{array}$ & France & $\begin{array}{l}6 \text { months } \\
\text { (November } 1999 \\
\text { to April 2000) }\end{array}$ & $\begin{array}{l}\text { Prospective } \\
\text { monocentre }\end{array}$ & $\begin{array}{l}\text { Teaching } \\
\text { hospital }\end{array}$ & $\begin{array}{l}\text { Medical ICU }(27 \\
\text { beds) }\end{array}$ & 528 & $\begin{array}{l}\text { Determine the incidence, risk factors, severity and preventability of IES } \\
\text { as cause of ICU admission }\end{array}$ \\
\hline $\begin{array}{l}\text { Nazer and } \\
\text { colleagues, } \\
2013 \text { [20] }\end{array}$ & Jordan & $\begin{array}{l}5 \text { months } \\
\text { (August to } \\
\text { December 2010) }\end{array}$ & $\begin{array}{l}\text { Prospective } \\
\text { monocentre }\end{array}$ & $\begin{array}{l}\text { Teaching } \\
\text { cancer } \\
\text { centre }(170 \\
\text { beds) }\end{array}$ & $\begin{array}{l}\text { Medico-surgical ICU } \\
\text { (12 beds) }\end{array}$ & 249 & $\begin{array}{l}\text { Describe the incidence, characteristics and cost of ADE that } \\
\text { necessitate admission to the ICU in oncology patients }\end{array}$ \\
\hline
\end{tabular}

ADE, adverse drug events; ADR, adverse drug reactions; CCU, coronary care unit; DII, drug-induced illness; ID, iatrogenic disease; IE, iatrogenic event; IGICE, Italian Group on Intensive Care Evaluation; ND, not

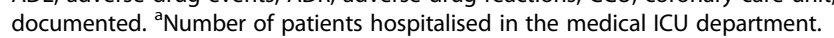


Table 4 Risk of bias in individual studies

\begin{tabular}{|c|c|c|c|c|c|c|c|c|c|c|c|}
\hline \multirow[b]{2}{*}{ Evaluated item } & \multicolumn{11}{|c|}{ Study } \\
\hline & [10] & [11] & [12] & [13] & [14] & [15] & [16] & [17] & [18] & [19] & [20] \\
\hline Prospective study design? & 1 & 1 & 1 & 0 & 1 & 1 & 1 & 1 & 1 & 1 & 1 \\
\hline Description of the type of studied ICU? & 1 & 1 & 1 & 1 & 1 & 1 & 1 & 1 & 1 & 0 & 1 \\
\hline Complementary information on the setting environment? & 0 & 0 & 0 & 1 & 0 & 0 & 0 & 1 & 1 & 0 & 0 \\
\hline Study size rationale? & 0 & 0 & 0 & 0 & 0 & 0 & 0 & 0 & 0 & 0 & 0 \\
\hline Definition of ADE according to IOM? & 0 & 0 & 0 & 0 & 0 & 0 & 0 & 0 & 0 & 0 & 1 \\
\hline Evaluation of inter-rater reliability for inclusion decision? & 0 & 0 & 0 & 0 & 0 & 0 & 0 & 0 & 0 & 0 & 0 \\
\hline Description of evaluators' training? & 1 & 1 & 1 & 1 & 1 & 1 & 1 & 1 & 1 & 1 & 1 \\
\hline Description of patients' screening? & 1 & 1 & 1 & 1 & 1 & 1 & 1 & 1 & 1 & 1 & 1 \\
\hline Description of inclusion/exclusion criteria? & 1 & 0 & 0 & 1 & 1 & 1 & 1 & 1 & 1 & 1 & 1 \\
\hline Description of collected data? & 1 & 1 & 0 & 1 & 0 & 1 & 1 & 0 & 1 & 1 & 1 \\
\hline Description of the drug history collecting method? & 0 & 0 & 0 & 0 & 0 & 0 & 1 & 0 & 0 & 0 & 0 \\
\hline Description of causality assessment method? & 1 & 0 & 1 & 1 & 1 & 0 & 1 & 1 & 1 & 1 & 0 \\
\hline Description of preventability method/criteria? & 0 & 0 & 1 & 1 & 1 & 1 & 1 & 1 & 0 & 1 & 1 \\
\hline Definition of ADE severity? & 1 & 1 & 0 & 1 & 0 & 0 & 1 & 1 & 1 & 0 & 0 \\
\hline Description of study duration? & 1 & 0 & 1 & 1 & 1 & 1 & 1 & 1 & 1 & 1 & 1 \\
\hline Results for incidence of ADE requiring ICU admission? & 1 & 1 & 1 & 1 & 1 & 1 & 1 & 1 & 1 & 1 & 1 \\
\hline Results for inter-rater reliability for inclusion decision? & 0 & 0 & 0 & 0 & 0 & 0 & 0 & 0 & 0 & 0 & 0 \\
\hline $\begin{array}{l}\text { Description of the characteristics of patients with ADE (age, gender, severity score at } \\
\text { admission, reason of admission, origin of patients)? }\end{array}$ & 0 & 1 & 0 & 0 & 0 & 0 & 1 & 0 & 0 & 0 & 0 \\
\hline $\begin{array}{l}\text { Description of number and classes of drugs suspected to be involved in the ADE } \\
\text { responsible for ICU admission? }\end{array}$ & 1 & 0 & 0 & 1 & 1 & 0 & 1 & 0 & 1 & 1 & 1 \\
\hline Results for causality assessment? & 1 & 0 & 0 & 1 & 0 & 0 & 1 & 1 & 0 & 0 & 0 \\
\hline Results for preventability rate? & 0 & 0 & 0 & 1 & 1 & 0 & 1 & 1 & 0 & 1 & 1 \\
\hline Results for ADE severity? & 1 & 1 & 0 & 1 & 0 & 0 & 1 & 1 & 1 & 0 & 1 \\
\hline Results for ICU mortality rate of patients with ADE? & 1 & 1 & 0 & 1 & 0 & 0 & 1 & 1 & 1 & 0 & 1 \\
\hline Results for the length of stay for patients with and without ADE (separately)? & 0 & 0 & 0 & 1 & 0 & 0 & 1 & 1 & 1 & 0 & 1 \\
\hline Proportion of items completely reported & 0.58 & 0.42 & 0.33 & 0.71 & 0.46 & 0.38 & 0.79 & 0.67 & 0.63 & 0.46 & 0.63 \\
\hline
\end{tabular}

$\mathrm{ADE}$, adverse drug events; IOM, Institute of Medicine.

other than ADE in only three studies [13,16,20], and comparisons involved various criteria from one study to another (see Additional file 3).

\section{Clarification of terminology and incidence of adverse drug events}

Five studies reported the incidence of $\mathrm{ADE}$ as a cause for ICU admission, ranging from 0.37 to $22.9 \%$ [13-15,19,20] (Additional file 4). Five studies reported more specifically the incidence of ADR, ranging from 0.53 to $27.4 \%$ $[11,12,16-18]$, and one study reported the combined incidence of $\mathrm{ADE}$ (5.9\%), ADR (4.0\%) and medication errors (1.9\%) potentially responsible for ICU admission [10].

\section{Characterisation of adverse drug events responsible for admissions to the ICU}

The mortality rate ranged from $2 \%$ [18] to $28.1 \%$ [20]. The preventability rate varied between $17.5 \%$ [20] and
85.7\% [17] (Table 5 and Additional file 3). Inter-rater agreement was only reported for the judgement of the preventability of iatrogenic medical events, and only in one study [15] - with a corresponding moderate interrater agreement (kappa test $=0.5$ ).

The leading causes of ADE were reported briefly. Trunet and colleagues underlined that ADE were due to 12 drug-drug interactions and 31 medication errors (28 overdosages and three cases of drug prescription in spite of contraindications) [10]. Darchy and colleagues described the causes of the 30 ADE: inadequate follow-up of therapy in $46.7 \%$ (14 cases), error in dose in $26.7 \%$ (eight cases), inappropriate drug in 20\% (six cases) and failure to use prophylactic treatment in $6.6 \%$ (two cases) [13]. Lehmann and colleagues categorised ADE into dosage error in $43 \%$ (nine cases), idiosyncratic reaction in $33 \%$ (seven cases), frequency error in 10\% (two cases), unclassified error in 10\% (two cases) and wrong drug to 
Table 5 Description of the adverse drug events requiring admissions to the ICU

Study Severity/type of scale and results, $\%(n)$ Drugs involved ${ }^{a}, \%$ of patients ( $n$ )

Preventability and categorisation if any

Psychotropic drugs, 17.5\% (17); anticoagulants, 13.4\% Not investigated

Trunet and

colleagues,

1986 [10]

IGICE, 1987

[11]

Nelson and

Talbert, 1996

[12]

Darchy and

colleagues, moderate, $73.2 \%$ (30)

Fatal, 14.6\% (6); life-threatening, 12.2\% (5)

1999 [13]

Hammerman Not investigated

and

Kapeliovich

2000 [14]

Lehmann Not investigated

and

colleagues,

2005 [15]

Grenouillet-

Delacre and

colleagues, [23]: life-threatening, 94\% (124); potential 2007 [16]
According to World Health Organization

Fatal, 9.3\% (9); life-threatening, 27.9\% (27)

Minor, 0\%; major, 100\%

Not investigated

life-threatening, 6.0\% (8); among these

events, 15.9\% (21) contributed to death
(13); intravenous solutions, $12.4 \%$ (12); antibiotics,

$11.4 \%$ (11); diuretics, 9.3\% (9) (44); ACE inhibitors, $45.3 \%$ (29); calcium antagonists, standard of care [22]
30 drugs involved in ADR; single drug, 83.3\% ADR (20); association of drugs, 16.7\% ADR (4)

ND specifically for ICU patients: hypoglycaemic drugs, $15.8 \%(12)^{\text {b }}$; diuretics, $13.2 \%(10)^{b}$; antiinfectious drugs, $11.8 \%(9)^{\mathrm{b}}$; cardiovascular drugs, $10.5 \%(8)^{b} ;$ psychotic drugs, $9.2 \%(7)^{b}$

55 drugs involved in ID; single drug, 22 IDs; association of drugs, 19 IDs; diuretics, $17.1 \%$ anticoagulants, $14.6 \%$ (6); nonsteroidal antiinflammatory, $14.6 \%$ (6); antibiotics, $14.6 \%(6)$; anaesthesia, $12.2 \%$ (5)

234 drugs involved in major IE; single drug, one major IE; association of drugs, 63 major IEs; nitrates, 76.6\% (49); diuretics, 70.3\% (45); beta-blockers, 68.8\% $43.8 \%(28)$

Narcotic analgesics, 42.8\% (9); sedative hypnotics, $23.8 \%(5)$

132 drugs involved; psychotropic drugs, 22.5\% (25); Definitely preventable - all conditions for avoidance Definitely preventable, 10.6\% immunosuppressive drugs, 21.6\% (24); anticoagulant of its occurrence were fulfilled drugs, 13.5\% (15); anti-infectious drugs, 12.6\% (14); antihypertensive drugs, $12.6 \%$ (14)
Not investigated

Definitely avoidable - satisfied by one of the following criteria: patient did not take a prescribed drug, known allergy to the drug, contraindication between the drug and his disease/condition, the patient took a drug not prescribed or not indicated for a diagnosed disease

Possibly avoidable: monitoring of the patient's drug therapy not inadequate

Not avoidable - no reasonable actions could have prevented it

Unevaluable - information is insufficient to make a determination or is contradictory

Event that should not occur if management is the

best that medical science can provide

Event that could have been avoided if the

prescription of therapy had respected the art of

medical practice

Event avoidable using any means currently

available, unless those means where not considered

ND specifically for ICU

(22); not preventable, $14.1 \%$

(9); not assessable, 51.6\% (33)

patients $(n)$

Not investigated

ND specifically for ICU

parts: definitely avoidable $49.3 \%(36)^{b}$

Possibly avoidable, $9.6 \%{ }^{\mathrm{b}}$ (7)

Not avoidable, $37.0 \%^{\mathrm{b}}$ (27)

Unevaluable, $4.1 \%^{\mathrm{b}}(3)$

$73.1 \%(30)$

$64.1 \%(41)$

Potentially preventable - not all conditions were met to avoid its occurrence

Not preventable - treatment procedure consistent with current knowledge of good medical practice (14)

Potentially preventable, $37.1 \%(49)$

Not preventable, $21.2 \%$ (28)

Not assessable (lack of data), $31.1 \%(41)$

$85.7 \%(18)$ 
Table 5 Description of the adverse drug events requiring admissions to the ICU (Continued)

Rivkin, 2007 Fatal, 19\% (4); severe, 66.7\% (14): moderate, 39 drugs involved; single drug, 43\% ADR (9):

Schwake and Life-threatening, 37.4\% (37); potentially lifecolleagues, threatening, 62.6\% (62); Among these 2009 [18] events $2 \%$ (2) were fata

Mercier and Not investigated

colleagues,

2010 [19]

Nazer and Fatal, 28.1\% (16); life-threatening, 17.6\%

$2012[20]$ associations of drugs, $57 \%$ ADR (12)

anticoagulants, 62.6\% (62); analgesics, 25.2\% (25); diuretics, 16.2\% (16); antihypertensives, 5\% (5);

antidepressants, 5\% (5)

54 drugs involved; chemotherapy,

immunosuppressant drugs, 27.8\% (15); psychotropic

drugs, 14.8\% (8); cardiovascular drugs, 14.8\% (8);

anaesthesia, analgesic drugs, $11.1 \%$ (6); oral

anticoagulants, 9.3\% (5)

Antineoplastic drugs: 64.9\% (37); analgesics: 15.8\%

(9): anticoagulants: $7 \%$ (4); others: $12.3 \%$ (7)
Medication use was inappropriate and contrary to

standard clinical practice [24]

Not investigated

Preventable ADR: drug not used according to the

summary of product characteristic

$64 \%(32)$

ADE met at least one of the following criteria

inappropriate drug or unnecessary for the patient's

condition, drug dose; route or frequency

inappropriate for the patient's age, weight or

disease state; required supportive/preventive

therapies not prescribed; required therapeutic drug

monitoring or laboratory tests not performed;

history of allergy; resulted from a well-established

drug interaction

$\overline{A C E}$, angiotensin-converting enzyme; ADE, adverse drug events; ADR, adverse drug reaction; ID, iatrogenic disease; IE, iatrogenic event; IGICE, Italian Group on Intensive Care Evaluation; ND, not documented. ${ }^{\mathrm{a} T h e}$ five

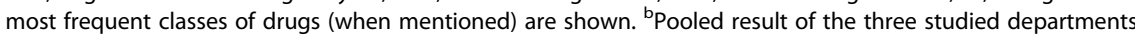


patient in 5\% (one case) [15]. Grenouillet-Delacre and colleagues mentioned that 87 of the 132 ADRs (66\%) were caused by interaction between drugs [16]. Finally, anaphylaxis or improper drug use were mentioned in the study by the Italian Group on Intensive Care Evaluation [11].

The most frequent drugs involved in $\mathrm{ADE}$ in the 11 studies were cardiovascular, anticoagulant and psychotropic drugs. Most ADE were preventable but the processes that had led to the corresponding drug misuse were poorly detailed.

\section{Causality results}

As shown in Table 6, the data required for assessing causality differ from one method to another. Various causality assessments were used, and results on causal assessments of ICU admissions related to ADE were mentioned in only four articles $[10,13,16,17]$.

\section{Risk of bias across studies}

Considering the 24 items retained for assessing the risk of bias in/across studies, nine (37\%) items were not reported or were incompletely reported in at least one-half of the studies (Figure 2), with five items related to methodology (out of 15) and four items related to results (out of nine).

\section{Synthesis of results}

The asymmetric shape of the funnel plot shown in Figure 3 indicates that large studies tend to report low estimates of the IDRIA. A forest plot adopting a random effects model resulted in a final estimate of the IDRIA at $7 \%(6 \% ; 8 \%)$, with a total sample size of 18,241 patients (Figure 4). However, because of the large heterogeneity of the studies ( $I^{2}$ statistic $\left.>98 \%\right)$, the above final estimate should not be considered a summary measure.

\section{Additional analyses Quality assessment}

The quality scores of the included studies varied from 0.36 [11] to $0.78[18,20]$, with a median (interquartile range) value of $0.61(0.59 ; 0.70)$, when assessment was based on STROBE items (Figure 5). The scores varied from 0.33 [12] to 0.80 [16] with a median (interquartile) value of $0.61(0.44 ; 0.69)$ when quality assessment was based on the checklist that we devised for considering specific items on ADE resulting in ICU admission (Table 2). The differences between the two scores varied highly from one study to another (Figure 5).

\section{Sensitivity analysis}

A first analysis was conducted with removal of the study by Lehmann and colleagues [15] (highest sample size and extremely low estimate of the IDRIA). A second analysis was conducted with the removal of the studies by Lehmann and colleagues and by the Italian Group on Intensive Care Evaluation (the two studies with the highest sample sizes and the lowest estimates of the IDRIA) $[11,15]$. A third analysis was conducted considering the six studies with the lowest risk of bias $[10,13,16-18,20]$ (see Table 4). The corresponding forest plots of these three analyses (data not shown) still indicated a large heterogeneity across the considered studies, and the $I^{2}$ statistic always remained above $96 \%$, confirming such heterogeneity.

\section{Discussion}

Our review of published reports regarding ICU admissions related to ADE identified 11 original studies. The IDRIA reported ranged from $0.37 \%$ [15] to $27.4 \%$ [16].

Vlayen and colleagues proposed a review on the incidence and preventability of adverse events that required intensive care (re)admission [31]. The adverse events considered by Vlayen and colleagues not only included ADE but also surgical procedures and medical devices, the population considered was adult and paediatric patients originating from hospital wards only, and the incidence of events was reported according to the total number of stays in the studied hospital ward(s). The perspective of our review was different: the events considered were strictly ADE as a cause of ICU admission, the patient population was adult patients (whatever the origin of the patient), and the incidence was reported according to the total number of admissions in ICU. These important perspective differences probably explain the fact that nine of the 11 articles retained in our study were not included in Vlayen and colleagues' study selection [31].

Our study outlines several methodological aspects that contribute to the observed wide range of the reported IDRIA, such as study setting (types of patients and ICU under study) and the type of drug-related events considered. The definition of ADE that was proposed by the Institute of Medicine and recommended by Nebeker and colleagues [4] should be adopted as it encompasses all aspects of ADE.

The methods used for assessing preventability of ADE also varied across studies, and either implicit or explicit criteria were used. Excepted for one study gathering a large proportion of febrile neutropenia, which is not preventable [20], the preventability rate in the seven other studies was high (lowest estimate 47.7\% [16]). However, a recent systematic review on the methods for assessing the preventability of ADE concludes that there is limited evidence for the validity of the identified instruments, and instrument reliability varied significantly [32]. Moreover, the single study that assessed inter-rater agreement for determining preventability resulted in a moderate 
Table 6 Causality results

Required data or study Causality assessment methods

\begin{tabular}{|c|c|c|c|c|c|c|}
\hline \multirow[t]{2}{*}{ kequirea aata or stuay } & \multicolumn{6}{|l|}{ Causality assessment metnoas } \\
\hline & Kramer and colleagues [25] & WHO [26] & $\begin{array}{l}\text { Naranjo and } \\
\text { colleagues [27] }\end{array}$ & Karch-Lasagna [28] & Hallas and colleagues [29] & Begaud and colleagues [30] \\
\hline $\begin{array}{l}\text { Required data for } \\
\text { causality assessment }\end{array}$ & L, Chron, D, R, LT, AEC & $\begin{array}{l}\text { L, Chron, D, } \\
\text { R, AEC, PP }\end{array}$ & $\begin{array}{l}\text { L, Chron, D, R, PI, DM, } \\
\text { LT, AEC, Atcd, OE }\end{array}$ & L, Chron, D, R, AEC & Chron, D, R, LT, AET, Atcd & L, Chron, D, R, LT, AEC, PP \\
\hline
\end{tabular}

$\begin{array}{ll}\text { Trunet and colleagues, } & \text { de, 29.7\% (30); pr, 45.6\% (46); } \\ 1986[10] & \text { po, 20.8\% (21); un, 3.9\% (4) }\end{array}$

IGICE, $1987[11]^{\mathrm{a}}$

Nelson and Talbert, 1996

[12]

Darchy and colleagues,

1999 [13]

Hammerman and

Kapeliovich, 2000 [14]

Lehmann and colleagues, 2005 [15]

Grenouillet-Delacre and

colleagues, 2007 [16]

Rivkin, 2007 [17]

Schwake and colleagues,

2009 [18]

Mercier and colleagues,

2010 [19]
pr, 59.6\% (31) ; po,
$40.4 \%(21)^{b}$
de, $15.3 \%(8)^{\text {b }} ;$ pr, $40.4 \%(21)^{\mathrm{b}} ;$ po
$25 \%(13)^{\text {b }}$; un, $19.3 \%(10)^{\mathrm{b}}$

de, $34.1 \%$ (14); pr, $34.1 \%$

(14); po, 31.8\% (13)

ND

ND

ND

de, $4.8 \%(1) ; \operatorname{pr}, 80.9 \%$

(17); po, $14.3 \%$ (3)

ND

Nazer and colleagues,

$2013[20]^{a}$

IGICE, Italian Group on Intensive Care Evaluation; ND, not documented; WHO, World Health Organization. Results of causality assessment methods: de, definite; po, possible; pr, probable; un, unlikely. Required data used for assessing causality in each method: AEC, alternative etiologic candidates (other than drugs); Atcd, antecedent of similar event to the same drug; Chron, chronology; D, clinical outcome after dechallenge; DM, clinical outcome after dose modification; L, description in the literature; LT, results of therapeutic drug monitoring or laboratory test; OE, adverse event confirmed by objective evidence; PI, clinical outcome after placebo administration; PP, explanation by pharmacologic properties; R, clinical outcome after rechallenge. ${ }^{\mathrm{a}}$ This study did not report causality assessment. ${ }^{\mathrm{b}}$ Pooled results for the three departments.
Very likely, $8.3 \%$ (11); likely, 51.5\% (68): possible, $40.2 \%(53)$ 


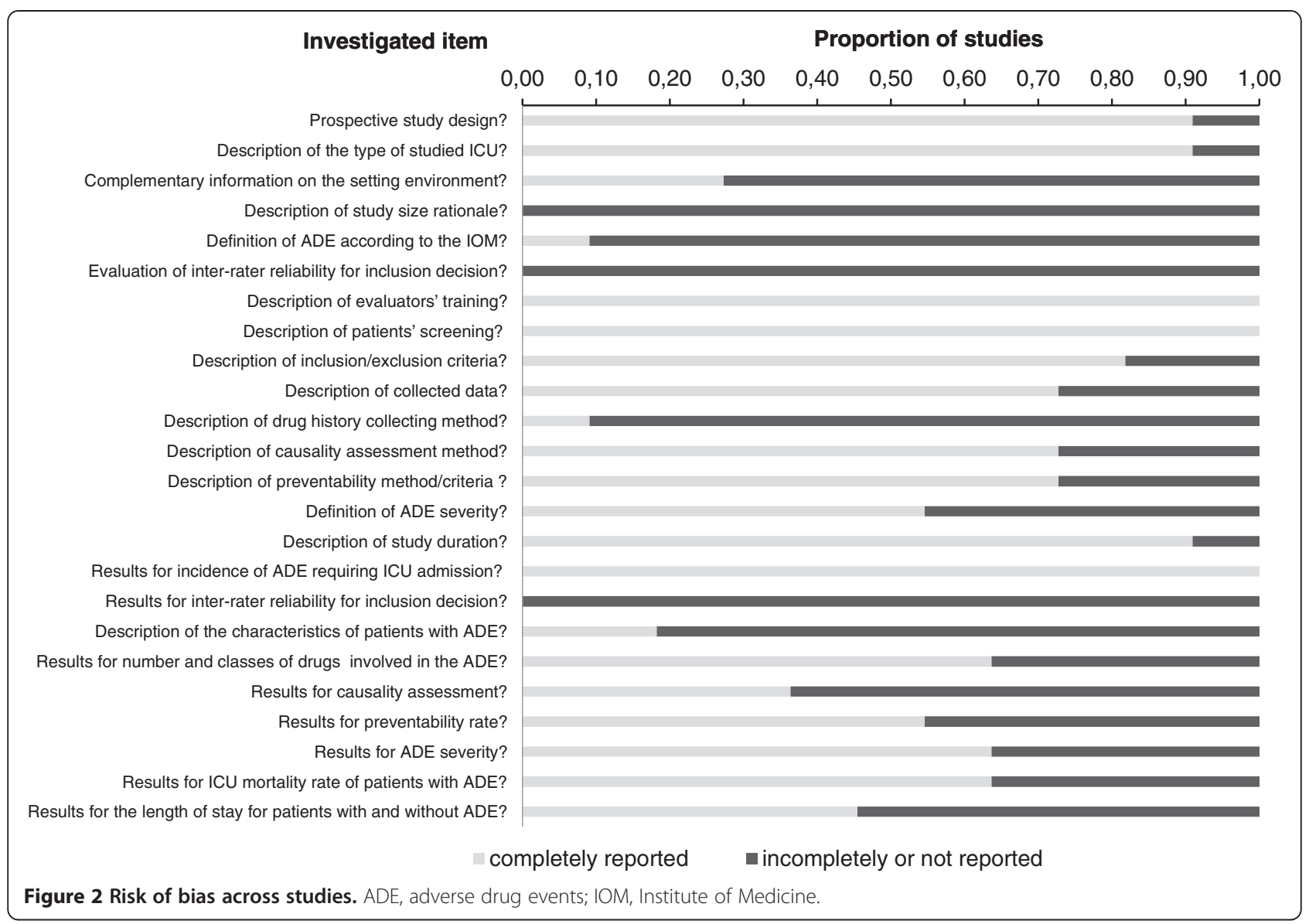

agreement [15]. All in all, a reliable and reproducible assessment of preventability remains a challenge at the present time.

Another source of heterogeneity was related to the causality assessment method. Kane-Gill and colleagues compared causality assessment methods (Naranjo, Kramer and Jones) in the ICU [33]. Agreement between the methods depended on whether events were judged retrospectively or were issued from a surveillance monitoring system. At the present time, the degree of agreement/disagreement between methods remains unclear. Most of all, existing tools widely used across different countries have not been customised to assess causality in the ICU. For example, the requirement of a procedure of rechallenge and dechallenge is a key element for assessing the certainty of the causality in the Naranjo, the Karch-Lasagna and the World Health Organization assessment methods. While one can understand the value of such an element with regard to causality strictly speaking, rechallenge is not possible most of the time in patients admitted to the ICU because of the seriousness of the drug-related events and poor patient health status. Moreover, the highest score for causality with these methods implies an improvement of the clinical features after dechallenge whereas recovery after dechallenge may be not achieved in ICU patients (irreversible organ failure, long-lasting effects of ADE). The events and patients involved in intensive care are therefore not well adapted to the above causality scales and, all in all, the design of a specific algorithm tailored to ICU cases would be welcome. Nevertheless, at the present time, the French official method by Begaud and colleagues, in which rechallenge or dechallenge is not a mandatory item for high causality scores, appears the best available tool [30].

Unsurprisingly, the most frequent drugs involved in ADE in the 11 studies are the same drugs that cause admission to emergency departments [34-36]. However, in order to better assess the dangerousness of these drugs, the frequencies of these ADE should be contrasted with the prescribing frequencies of the corresponding drugs. Exploring these relationships constitutes an important issue that deserves investigation. These investigations would facilitate the identification of specific patterns related to preventable $\mathrm{ADE}$ requiring ICU admissions. In that regard, the use of effective identification and reporting systems based on a consistent terminology should contribute to the design of preventive measures for avoiding such events. 


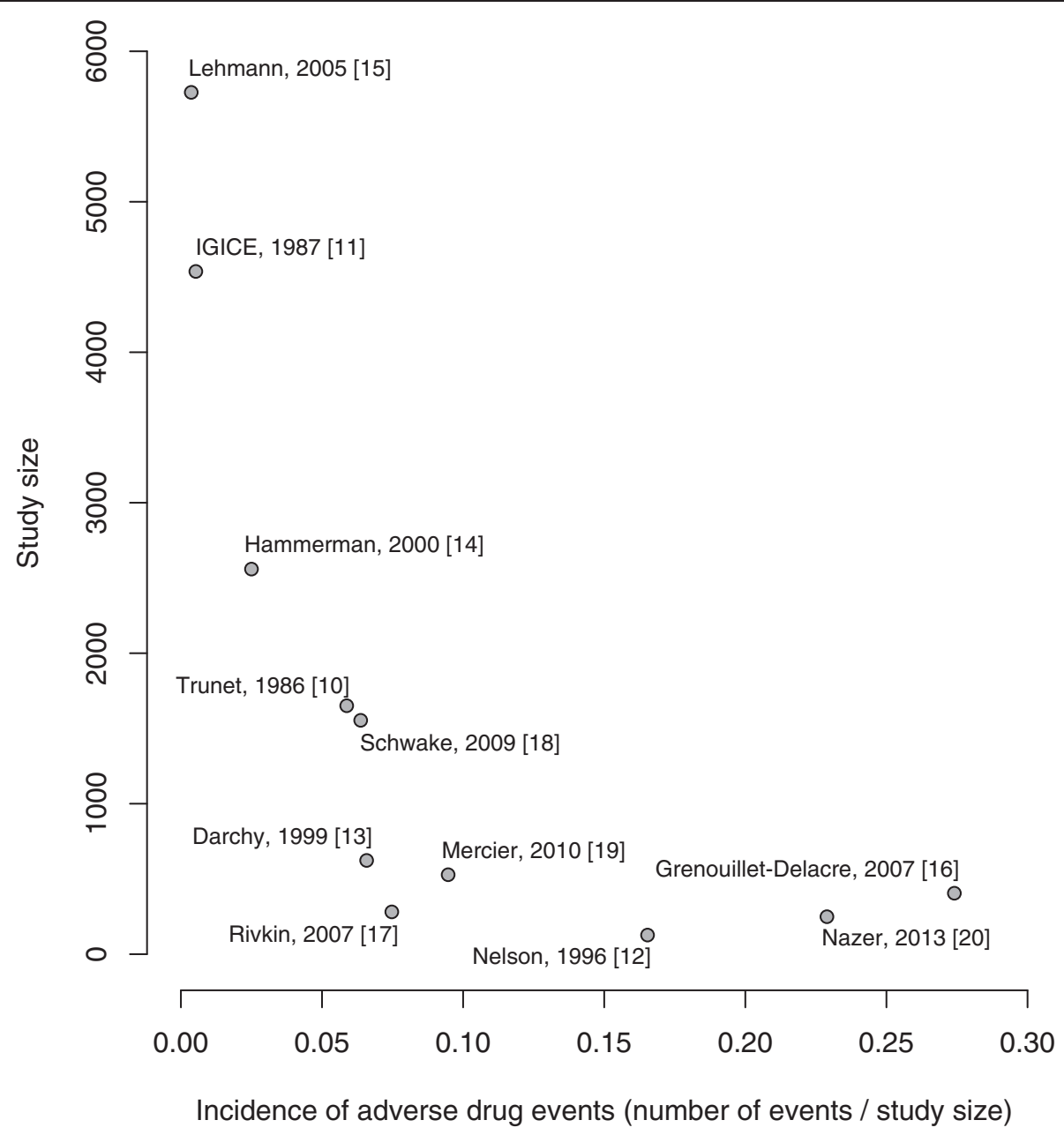

Figure 3 Funnel plot of the incidence of admissions to the ICU required due to adverse drug events [10-20]. IGICE, Italian Group on Intensive Care Evaluation.

In our review, quality assessment of the 11 articles not only included global STROBE recommendations but also items specific to the domain of critical care. The quality of reporting assessed according to STROBE items and according to our proposed items (see Table 2) resulted in identical median scores of 0.61 (see Figure 5), indicating that the quality of reporting for future research is substantially improvable. In addition, the within-study difference between the two above quality scores (Figure 5) indicates that the quality of reporting with regards to the global form (quality according to STROBE guidelines) may substantially differ from the value of the information reported according to a perspective focusing on the report of $\mathrm{ADE}$ in intensive care patients (quality of items specific to the ICU).

In this regard, our corresponding specific items might also be considered as a potential future checklist: experts in critical care could use this list and the associated scores as an initial proposal for developing international guidelines aimed at improving the quality of future research on
ADE-related ICU admissions. The use of this checklist should also decrease the risk of bias within and across studies.

This review has some limitations. The fact that only 11 studies were published during the last three decades may be related to two major elements. First, investigations into $\mathrm{ADE}$ in the intensive care setting require time-consuming resources and complex data. In that regard, the expanding availability of healthcare systems based on electronic medical records should facilitate future research on large cohorts of patients. Second, publication bias should be considered: one might hypothesise that studies reporting a high frequency of $\mathrm{ADE}$ requiring ICU admission are less likely to be published than those associated with a low estimate. The retrieved studies show a wide range for the IDRIA, however, and publication bias may therefore be limited. In addition, we only selected articles written in English, because we did not have the resources available to translate potential articles written in various other languages. Moreover, when considering a given study, only the quality of 


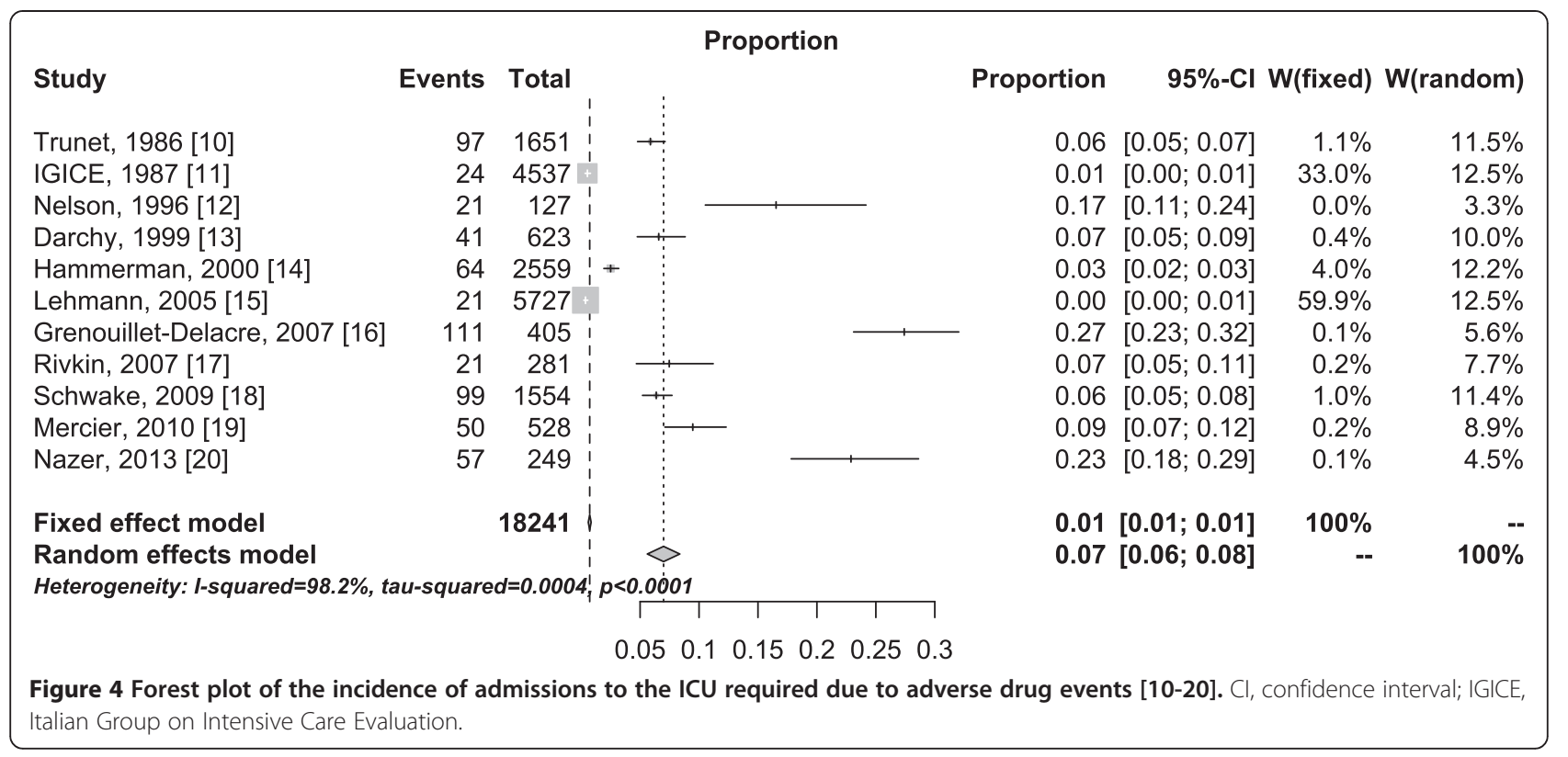

reporting was assessed. The major and important limitation of the review concerns the heterogeneity observed across studies for the definitions of events (ADE, ADR) and for the methods used for causality, preventability and severity assessment. Forest plot analyses of the IDRIA reflect such heterogeneity, which remained very high in the sensitivity analyses excluding some studies. Similarly, the asymmetric shape of the funnel plot also raises concerns. Heterogeneity and biases therefore finally constitute the main issue of the present review, in contrast to other reviews for which the final estimate issued from the meta-analysis is the main result.

\section{Conclusion}

Few studies dealt with ADE as a cause of admission to the ICU during the last three decades. The IDRIA reported

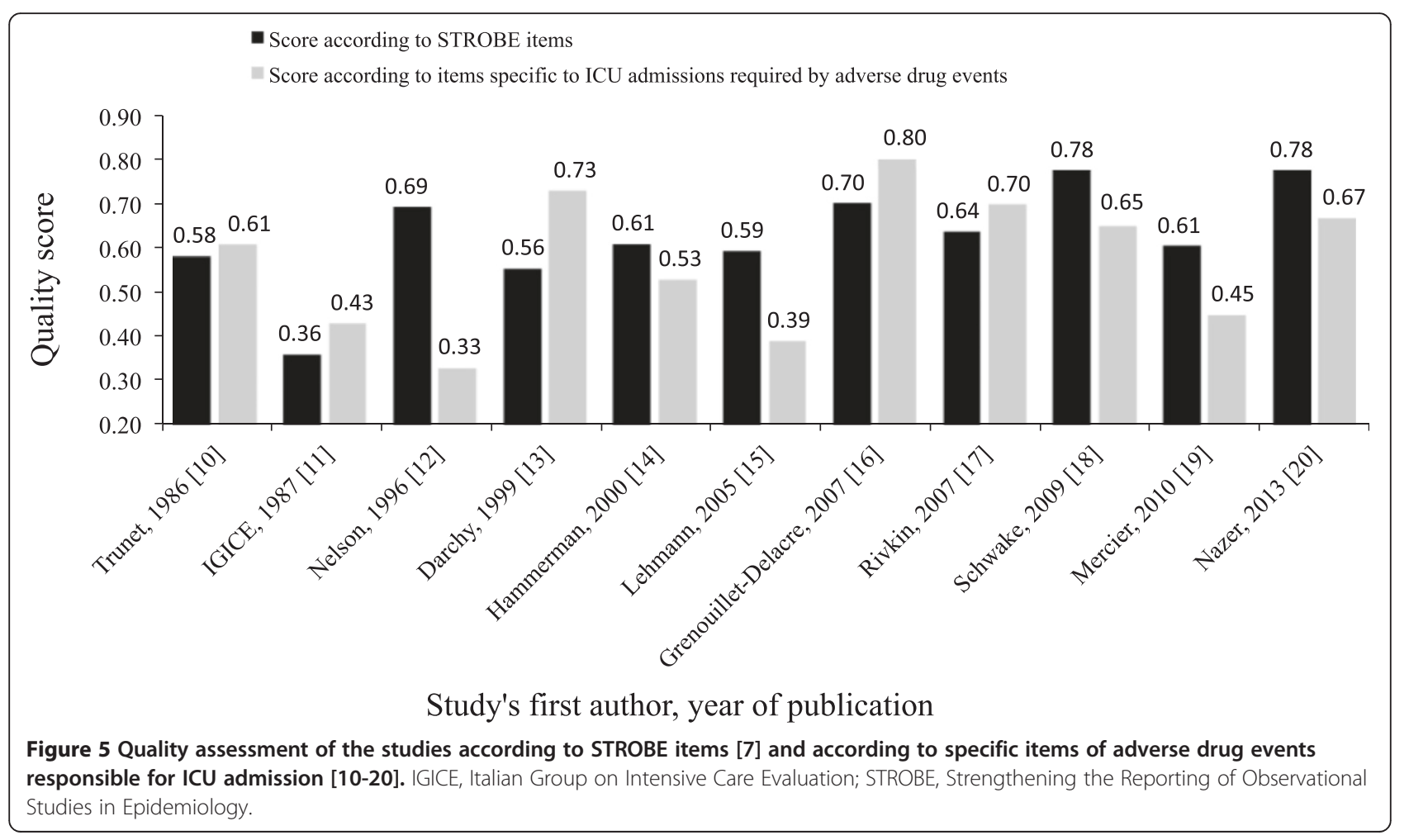


varied within a large range, from 0.37 to $27.4 \%$. Severity evaluation and the mortality rate are characteristics of major importance in ICU patient populations and these features should be explored and analysed in future studies. To encompass all aspects of ADE, compliance issues as well as lack of access to care should be investigated. Finally, methodological aspects should be enhanced in order to improve the quality of reports and limit risks of bias. In this regard, we propose a checklist (Table 2) specifically tailored to the topic of ADE requiring ICU admission that could be used as a helpful guide for future studies.

\section{Additional files}

Additional file 1: List of the search strategies.

Additional file 2: Table AF1. Assessment for eligibility of full-text articles: the 39 excluded articles.

Additional file 3: Table AF2. Population characteristics.

Additional file 4: Table AF3. Clarification of event terminology and incidence of event-related admissions in the ICU.

\section{Abbreviations}

ADE: Adverse drug events; ADR: Adverse drug reaction; IDRIA: Incidence of drug-related ICU admissions; STROBE: Strengthening the Reporting of Observational Studies in Epidemiology.

\section{Competing interests}

The authors declare that they have no competing interests.

\section{Authors' contributions}

All authors participated in the conception and design of the study. PAJ, PH and GH collected, analysed and interpreted data, and wrote the initial draft. All authors read and approved the final manuscript.

\section{Acknowledgements}

The authors are indebted to $D$ Benoist and C Weill at the Bibliothèque Interuniversitaire de Santé for their helpful assistance in bibliographic searches. We have no funding to report.

\section{Author details}

'Institut Pierre Louis d'Epidémiologie et de Santé Publique, Sorbonne Universités, UPMC Univ Paris 06, UMR_S 1136, F-75013 Paris, France. ${ }^{2}$ Institut Pierre Louis d'Epidémiologie et de Santé Publique, INSERM, UMR S 1136 , F-75013 Paris, France. ${ }^{3}$ AP-HP, Hôpital Saint-Antoine, Service de Pharmacie, F-75012 Paris, France. ${ }^{4}$ Univ Paris-Sud, Faculté de Pharmacie, F-92296 Chatenay-Malabry, France. ${ }^{5}$ AP-HP, Hôpital Saint-Antoine, Service de Réanimation, F-75012 Paris, France. ${ }^{6} \mathrm{AP}-\mathrm{HP}$, Hôpital Saint-Antoine, Unité de Santé Publique, F-75012 Paris, France.

Published online: 25 November 2014

\section{References}

1. Kongkaew C, Noyce PR, Ashcroft DM: Hospital admissions associated with adverse drug reactions: a systematic review of prospective observational studies. Ann Pharmacother 2008, 42:1017-1025.

2. Evans TW, Nava S, Mata GV, Guidet B, Estenssoro E, Fowler R, Scheunemann $L P$, White $D$, Manthous CA: Critical care rationing: international comparisons. Chest 2011, 140:1618-1624.

3. Rhodes A, Ferdinande P, Flaatten H, Guidet B, Metnitz PG, Moreno RP: The variability of critical care bed numbers in Europe. Intensive Care Med 2012, 38:1647-1653.

4. Nebeker JR, Barach P, Samore MH: Clarifying adverse drug events: a clinician's guide to terminology, documentation, and reporting. Ann Intern Med 2004, 140:795-801.
5. The Importance of Pharmacovigilance. Safety Monitoring of Medicinal Products. In [http://apps.who.int/medicinedocs/pdf/s4893e/s4893e.pdf]

6. WHO Draft Guidelines for Adverse Event Reporting and Learning Systems. In [http://www.who.int/patientsafety/events/05/ Reporting_Guidelines.pdf]

7. Vandenbroucke JP, von Elm E, Altman DG, Gotzsche PC, Mulrow CD, Pocock SJ, Poole C, Schlesselman JJ, Egger M: Strengthening the Reporting of Observational Studies in Epidemiology (STROBE): explanation and elaboration. PLOS Med 2007, 4:e297.

8. Liberati A, Altman DG, Tetzlaff J, Mulrow C, Gotzsche PC, loannidis JP, Clarke M, Devereaux PJ, Kleijnen J, Moher D: The PRISMA statement for reporting systematic reviews and meta-analyses of studies that evaluate healthcare interventions: explanation and elaboration. BMJ 2009, 339:b2700.

9. Schwarzer G: meta: an R package for meta-analysis. $R$ News 2007, 7:40-45.

10. Trunet $P$, Borda IT, Rouget $A V$, Rapin M, Lhoste F: The role of drug-induced illness in admissions to an intensive care unit. Intensive Care Med 1986, 12:43-46.

11. Italian Group on Intensive Care Evaluation: Epidemiology of adverse drug reactions in intensive care units: a multicentre prospective survey. Eur J Clin Pharmacol 1987, 31:507-512.

12. Nelson KM, Talbert RL: Drug-related hospital admissions. Pharmacotherapy 1996, 16:701-707.

13. Darchy B, Le Miere E, Figueredo B, Bavoux E, Domart Y: latrogenic diseases as a reason for admission to the intensive care unit: incidence, causes, and consequences. Arch Intern Med 1999, 159:71-78.

14. Hammerman H, Kapeliovich M: Drug-related cardiac iatrogenic illness as the cause for admission to the intensive cardiac care unit. Isr Med Assoc J 2000, 2:577-579.

15. Lehmann LS, Puopolo AL, Shaykevich S, Brennan TA: latrogenic events resulting in intensive care admission: frequency, cause, and disclosure to patients and institutions. Am J Med 2005, 118:409-413.

16. Grenouillet-Delacre M, Verdoux H, Moore N, Haramburu F, Miremont-Salame G, Etienne G, Robinson P, Gruson D, Hilbert G, Gabinski C, Begaud B, Molimard M: Life-threatening adverse drug reactions at admission to medical intensive care: a prospective study in a teaching hospital. Intensive Care Med 2007, 33:2150-2157.

17. Rivkin A: Admissions to a medical intensive care unit related to adverse drug reactions. Am J Health Syst Pharm 2007, 64:1840-1843.

18. Schwake L, Wollenschlager I, Stremmel W, Encke J: Adverse drug reactions and deliberate self-poisoning as cause of admission to the intensive care unit: a 1-year prospective observational cohort study. Intensive Care Med 2009, 35:266-274.

19. Mercier E, Giraudeau B, Ginies G, Perrotin D, Dequin PF: latrogenic events contributing to ICU admission: a prospective study. Intensive Care Med 2010, 36:1033-1037.

20. Nazer LH, Eljaber R, Rimawi D, Hawari Fl: Adverse drug events resulting in admission to the intensive care unit in oncology patients: incidence, characteristics and associated cost. J Oncol Pharm Pract 2013, 19:298-304.

21. Trunet P, Le Gall JR, Lhoste F, Regnier B, Saillard Y, Carlet J, Rapin M: The role of iatrogenic disease in admissions to intensive care. JAMA 1980, 244:2617-2620.

22. Bates DW, Cullen DJ, Laird N, Petersen LA, Small SD, Servi D, Laffel G, Sweitzer BJ, Shea BF, Hallisey R, Vander Vliet M, Nemeskal R, Leape LL: Incidence of adverse drug events and potential adverse drug events: implications for prevention ADE Prevention Study Group. JAMA 1995, 274:29-34.

23. Lindquist M, Edwards IR: The WHO Programme for International Drug Monitoring, its database, and the technical support of the Uppsala Monitoring Center. J Rheumatol 2001, 28:1180-1187.

24. Schumock GT, Thornton JP: Focusing on the preventability of adverse drug reactions. Hosp Pharm 1992, 27:538.

25. Kramer MS, Leventhal JM, Hutchinson TA, Feinstein AR: An algorithm for the operational assessment of adverse drug reactions. I. Background, description, and instructions for use. JAMA 1979, 242:623-632.

26. The Use of the WHO-UMC System for Standardised Case Causality Assessment. In [http://www.who-umc.org/Graphics/26649.pdf]

27. Naranjo CA, Busto U, Sellers EM, Sandor P, Ruiz I, Roberts EA, Janecek E, Domecq C, Greenblatt DJ: A method for estimating the probability of adverse drug reactions. Clin Pharmacol Ther 1981, 30:239-245.

28. Karch FE, Lasagna L: Toward the operational identification of adverse drug reactions. Clin Pharmacol Ther 1977, 21:247-254. 
29. Hallas J, Harvald B, Gram LF, Grodum E, Brosen K, Haghfelt T, Damsbo N: Drug related hospital admissions: the role of definitions and intensity of data collection, and the possibility of prevention. J Intern Med 1990, 228:83-90.

30. Begaud B, Evreux JC, Jouglard J, Lagier G: Imputation of the unexpected or toxic effects of drugs: Actualization of the method used in France. Therapie 1985, 40:111-118.

31. Vlayen A, Verelst S, Bekkering GE, Schrooten W, Hellings J, Claes N: Incidence and preventability of adverse events requiring intensive care admission: a systematic review. J Eval Clin Pract 2012, 18:485-497.

32. Hakkarainen KM, Andersson Sundell K, Petzold M, Hagg S: Methods for assessing the preventability of adverse drug events: a systematic review. Drug Saf 2012, 35:105-126.

33. Kane-Gill SL, Forsberg EA, Verrico MM, Handler SM: Comparison of three pharmacovigilance algorithms in the ICU setting: a retrospective and prospective evaluation of ADRs. Drug Saf 2012, 35:645-653.

34. Queneau P, Bannwarth B, Carpentier F, Guliana JM, Bouget J, Trombert B, Leverve X, Lapostolle F, Borron SW, Adnet F: Emergency department visits caused by adverse drug events: results of a French survey. Drug Saf 2007, 30:81-88.

35. Trinh-Duc A, Doucet J, Bannwarth B, Trombert-Paviot B, Carpentier F, Bouget J, Queneau P: Admissions of elderly to French emergency departments related to adverse drug events. Therapie 2007, 62:437-441.

36. Chen YC, Fan JS, Hsu TF, Chen MH, Huang HH, Cheng KW, Yen DH, Huang MS, Lee $\mathrm{CH}$, Chen LK, Yang CC: Detection of patients presenting with adverse drug events in the emergency department. Intern Med J 2012, 42:651-657.

doi:10.1186/s13054-014-0643-5

Cite this article as: Jolivot et al:: A systematic review of adult admissions to ICUs related to adverse drug events. Critical Care 2014 18:643. 